\title{
Arduino based Dialyser Reprocessing System
}

\section{Sunil Tej Boppudi, Hasya Reddy Reddivari, Ramanukolanu Sai Deepthi, Guggilam Ramesh Babu}

\begin{abstract}
Hemodialysis is a process of eliminating metabolic wastes from the blood in humans who suffer with renal failure or End Stage Renal Disease (ESRD). In the heart of the purifying process lies an exchanging apparatus called the Dialyzer, where it acts as a semipermeable membrane for the blood metabolic constituents to get eliminated from the system and sometimes excess water is also eliminated based on the patient's condition. These dialyzers are available in commercial market in two variants, one as a disposable and another as a reusable, where the latter can be multiple cycles of purification. In order to be useful for the multiple times or multiple cycles, a dialyzer is put in the dialyzer reprocessing unit (DRU). A DRU will ensure that the biological fluid is cleaned and disinfected with various fluids, filled with bacteria repellent fluid for later usages. DRUs are increasingly expensive in commercial aspects, in this paper a low cost dialyzer reprocessing prototype has been fabricated using an Arduino UNO board for the process control using R.O Water, Hydrogen peroxide and formalin as cleansing and disinfectant agents.
\end{abstract}

Keywords: Dialyzer; Dialyzer reprocessing unit(DRU); Hemodialysis; End stage Renal Disease; R.O. water; Formalin; Hydrogen Peroxide.

\section{INTRODUCTION}

From the time the hemodialysis was invented, patients who are depending on the hemodialysis are increasingly at a constant rate of 7-9\%. At the same time there was a trend to use hi-flux dialyzers which are comparatively more expensive than low flux dialyzers. As per the statistics of [2] in the USA alone there has been an increase in the patients who are treated with hi-flux dialyzers which is from 5 to $31 \%$ in years 1987 to 1994 . Similarly, in year 1994, $43.5 \%$ of patients in japan underwent high- flux dialysis. And there has been reported cases of use of various figures in entire Europe. [1]

In practice, dialyzer is reused for a single patient for multiple treatments using same dialyzer. Dialyzer reprocessing is the term used for the dialyzer to be used for next set of treatments. The procedure comprises of cleaning the dialyzer, validating the cleaned procedure and filling it with a relevant sterilizing fluid following which it is labeled and stored. For the next treatment procedure this stored dialyzer id rinsed and reused.

Revised Manuscript Received on December 15, 2019.

Sunil Tej Boppudi*, Biomedical Engineering, Department of ECE, Vignan's Foundation for Science Technology and Research, Guntur, A.P., India-522213. E-mail: suniltejb@gmail.com

Hasya Reddy Reddivari, Biomedical Engineering, Department of ECE, Vignan's Foundation for Science Technology and Research, Guntur, A.P., India-522213

Ramanukolanu Sai Deepthi, Biomedical Engineering, Department of ECE, Vignan's Foundation for Science Technology and Research, Guntur, A.P., India-522213

Guggilam Ramesh Babu, Biomedical Engineering, Department of ECE, Vignan's Foundation for Science Technology and Research, Guntur, A.P., India-522213
The said procedure is carried out in the safe governance of a dialyzer person. This procedure will safeguard form improper reuse of a dialyzer.

This process has been in place in the United Sates since 1960s and is a common practice for the dialysis treatments.

Another advantage of the Dialyzer reprocessing is that it can lower the slight rejection of the dialyzer after the first use. This is because, during the blood's first contact with the dialyzer's semipermeable membrane, the immune system will have some slight rejection. The rejection by the immune system is lowered further as the dialyzer is reused.

Ethylene Oxide (ETO) is a one of the sterilizing fluids that most of the dialyzer manufacturing companies use for the storing purpose before any dialysis process begins. This procedure for preparing the dialyzer before connecting to the dialysis patient circuit is called priming. This will ensure that no sterilant or preservative is passed into the human circulatory system. Quality assurance should also be in place for the dialyzer ensured of flushed out preservatives [3].

Another advantage of DRU or process is, it will reduce the raw materials that are used in the case of the disposable dialyzers, and also reduce the manufacturing costs. This in turn is also reduces the cost of the emissions, disposal costs, and landfilling wastes. Moreover, if this is compared to the generally used sterilant i.e. Renalin, breaks down natural products into by products such as, acetic acid, water and oxygen.

To compare the quantity of the dialyzers used in the case of disposable and reusable dialyzers, there is a drastic difference in terms of wastage. In the case of disposable dialyzers, the dialyzers required are 156 per annum if dialyzer is used thrice a week. However, if a DRU is used for dialyzer cleaning, a dialyzer can be used 16 times, which leads to usage of 10 dialyzers per annum. So, 146 dialyzers can be saved by implementing the DRU. In order to show the big picture of the savings, there are around $3,25,000$ people who get dialysis treatment in USA. These are some of the many reasons why a DRU is important for the Dialysis care units [4].

\section{MATERIALS \& METHODS}

The entire process of reprocessing includes electronic components for the control of instruments; and

Typical components of a development board and other materials include:

1. Power circuit (typically, set up to run from a 9V/12V power supply).

2. Arduino UNO board.

3. Basic output circuitry, such as LEDs.

4. 2 Unit Relay X 3 for controlling Led and Solenoid valves.

5. For a dialyzer, 'Brovondove's Pristine BD 130 UNO' with semipermipermiable membrane 'Polyethersulphone' was used. The total surface area of the dialyzer for dialysis is $1.3 \mathrm{~m}^{2}$. This is a hollow fibre dialyzer used in Controlled ultrafiltration mode. 
6. For pumping the various fluids into the dialyzer, 3 submersible pumps were used which generates a pressure of 2.5 psi. since this is a prototype only small amount of pressure generating pump was chosen. 3 in number

7. In order for the flow of the various fluids to be controlled, solenoid valves are used. In this case 'Herowater's' HR2, which is operated at 24V DC of 3 in number were used. This can with stand pressures up to 120 psi.

8. SPST relay for opening and closing motors and solenoid valves of 3 in number was used.

9. R.O Water was used to remove the minute particles \&

blood stains in the dialyzer at 2.5Psi.

10. Hydrogen peroxide was used for disinfection of dialyzer.

11. Formalin was used to keep bacteria away during the storing period.

A power supply connected to a suitable source of electrical power. For tubing RO water purifier tubing was used. Three reservoirs of concentrated cleaning solution (R.O Water, Hydrogen peroxide) and disinfecting solution (formalin) were connected to the valve via tubing. A logic circuit arduino UNO was connected to said power supply was connected and programmed to perform a desired reuse operation cycle

\section{EXPERIMENTS AND RESULT DESCRIPTION}

The complete process of cleaning or sterilization involves three steps through Arduino development board and 8051 developer board for power supply to relays and external 24 volt power supply to 10 psi water pump.:

1) To first cleanse/ clean or to remove any blood constituents from the dialyzer, R.O was pumped for 15 seconds.

2) In the second step, hydrogen peroxide was pumped into dialyzer for ten seconds to sterilize it for possible pathogens, bacteria.

3) In the final step, formalin is pumped for three seconds and filled; this serves a storing fluid to keep the bacteria away from polluting the dialyzer until ready for next usage.

\section{4) Relays for switching on}

In the building of the circuit 8051 microcontroller was used for controlling the relay switches and solenoid valves. And written a code for port-0

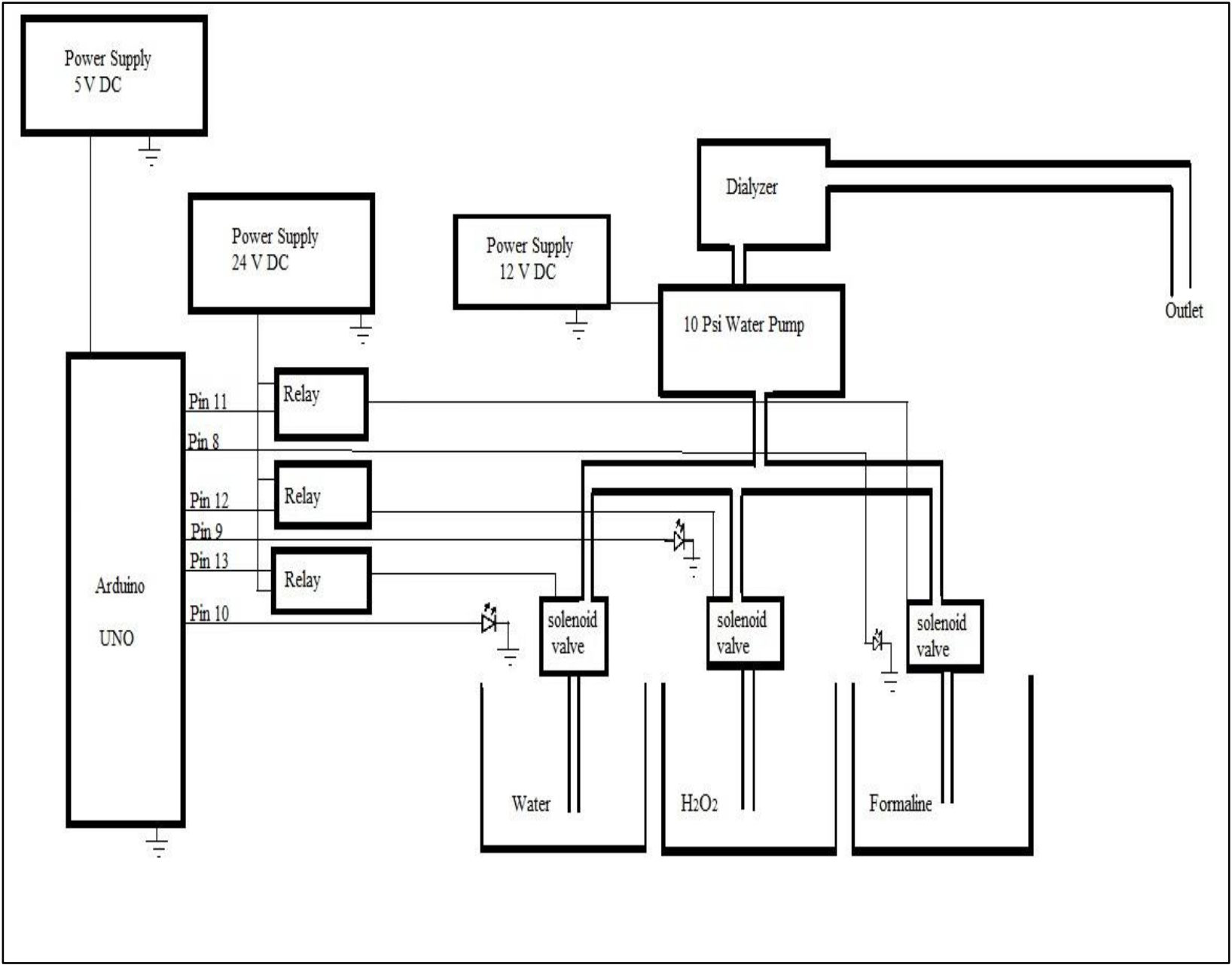

Fig 1: Showing the block diagram of Dialyzer reprocessing system. 
Code:

void $\operatorname{setup}()$

\{

pinMode(13, OUTPUT); // Output pin for solenoid of water container

pinMode(12, OUTPUT); // Output pin for solenoid of $\mathrm{H}_{2} \mathrm{O}_{2}$ container

pinMode(11, OUTPUT); // Output pin for solenoid of formalin container

pinMode(8, OUTPUT); // Output pin for LED of

water container

pinMode(9, OUTPUT); // Output pin for LED of

$\mathrm{H}_{2} \mathrm{O}_{2}$ container

pinMode(10, OUTPUT); // Output pin for LED of

formalin container

\}

void $\operatorname{loop}()$

\{

digitalWrite(13, LOW);

digitalWrite(12, HIGH);

digitalWrite(11, HIGH);

digitalWrite(10, HIGH);

digitalWrite(9, LOW);

digitalWrite(8, LOW);

delay(60000);

digitalWrite(13, HIGH);

digitalWrite(12, LOW);

digitalWrite(11, HIGH);

digitalWrite(10, LOW);

digitalWrite(9, HIGH);

digitalWrite(8, LOW);

delay(30000);

digitalWrite(13, HIGH);

digitalWrite(12, HIGH);

digitalWrite(11, LOW);

digitalWrite(10, LOW);

digitalWrite(9, LOW);

digitalWrite(8, HIGH);

delay(30000);

\}

The process logic for the control system is, at any given time only one solenoid valve is open and one LED is ON. The 10 Psi Pump is on always.

\section{CONCLUSION AND DISCUSSIONS}

It has been thought that in order for the sytem to be more efficient interms of cost, instead of pumping the dialyzer with hydrogen peroxide and formaline, they can be filled noramlly. i.e. by the help of gravity.

\section{ACKNOWLEDGEMENT}

I would like to extend special thanks Mr. N.S.B. Reddy, Service Engineer, B'Braun. Vijayawada, India, for sharing his practical knowledge in the development of this system.

\section{REFERENCES}

1. José Vinhas, João Pinto dos Santos; Haemodialyser reuse: facts and fiction, Nephrology Dialysis Transplantation, Volume 15, Issue 1, 1 January 2000, Pages 5-8,

2. Tokars JI, Alter MJ, Miller E, Moyer LA, Favero MS. National surveillance of dialysis associated diseases in the United States1994. ASAIO J 1997; 43: 108-119

3. Medicators.com' patient's Guide to Dialyzer reprocessing system'.( http://www.medivators.com/sites/default/files/minntech/documents/5 0096-364\%20RevB.pdf)

4. 'How a Dialyzer is Made', A publication on dialyzer reprocessing. Re News, Minntech Corporation ,P/N 50096-799A ; volume 12, 2007. 